\title{
The effect of lightness contrast on the colored Müller-Lyer illusion
}

\author{
ROBERT H. POLLACK \\ University of Georgia, Athens, Georgia \\ and \\ THEODORE B. JAEGER \\ Westminster College, Fulton, Missouri
}

\begin{abstract}
Two subjects estimated the length of the central line in red and blue Müller-Lyer figures that were viewed both foveally and parafoveally. The illusion figures were defined by either lightness and hue differences between figure and ground or by a hue difference alone. For both subjects, the figures defined solely by hue produced larger illusions. Since depth-cue scaling and other cognitive factors did not cause the enlargement, it was concluded that the robust, hue-produced illusions resulted from contour interactions generated within parvocellular channels that are specialized for coding color.
\end{abstract}

Many studies (Coren, Girgus, Ehrlichman, \& Hakstian, 1976; Coren \& Porac, 1984; Coren \& Ward, 1979; Greist-Bousquet, \& Schiffman, 1981; Sadza \& de Weert, 1984) have indicated that the Müller-Lyer illusion results from the composite action of several length-distorting processes. The implicated processes may be categorized according to their origins. Some, such as contour displacements (Ganz, 1966; Pollack, 1964; Pollack \& Chaplin, 1964) and interactions among neural length detectors (Brigell \& Uhlarik, 1979; Brigell, Uhlarik, \& Goldhorn, 1977; Brigner, 1977), are clearly sensory in nature, whereas others, such as depth-cue scaling (Gillam, 1980; Gregory, 1963, 1968), assimilation (Pressey, 1967, 1971; Pressey \& Murray, 1976), centration (Piaget, 1969), and confusion (Erlebacher \& Sekuler, 1969), have a cognitive basis.

Proceeding from this sensory and cognitive differentiation, Coren (1970) compared the magnitudes of the dot and conventional forms of the Müller-Lyer illusion and found that the dot form, which emerges when only the endpoints of the lines of the conventional figure are present, creates a $30 \%$ weaker illusion. This reduction was attributed to the absence of intersecting linear contours in the dot figure and the resulting elimination of contour-induced, lateral inhibitory interactions. The remaining 70\% of the illusion was left to be explained by other, presumably cognitive, mechanisms that are unaffected by the intersecting wings. Subsequently, Girgus, Coren, Durant, and Porac (1975) utilized decrement of the Müller-Lyer illusion produced by prolonged inspection of the stimulus figure as a tool to separate sensory

Correspondence should be addressed to Robert H. Pollack, Department of Psychology, University of Georgia, Athens, GA 30602. and cognitive contributions. Such decrement, they argue, results from a reorganization of underlying cognitive strategies for extracting length. Thus, their demonstration that the magnitude of the Müller-Lyer illusion reduces to approximately two thirds of its original size after five daily 10-min exposure sessions is taken to indicate that $35 \%$ of the illusion must be attributed to cognitive factors, while the remaining $65 \%$ reflects the more permanent sensory basis of the illusion. Yet more recently, Coren and Porac (1984) and Predebon (1986) have claimed that sensory and cognitive components each play approximately a $50 \%$ role in the Müller-Lyer illusion, whereas Wenderoth and Wade (1981) have placed the proportions at $68 \%$ sensory and $32 \%$ cognitive.

Although the explanation of the Müller-Lyer illusion would clearly be made easier if one could quantify the relative contributions of sensory and cognitive factors, the estimations above vary. Worse, the arguments that have led to these estimations may be flawed. Consider, for example, that the dot Müller-Lyer may weakly stimulate interactions among neural length detectors (see Brigner, 1977) and therefore may not purely measure the cognitive component of the illusion, and further, that the processes responsible for the cognitive component may not recalibrate themselves to complete veridicality as a result of simple inspection.

Because of these concerns, it seems advantageous to explore alternative methods of assessing the relative importance of sensory and cognitive contributions to the illusion. One such method is suggested by Livingstone and Hubel's (1988) segregation of the visual system into three channels for the coding of depth and movement, color, and static form. Of particular importance here is the proposition that their magnocellular channel, normally utilized for processing depth and movement, is not sensi- 
tive to color and therefore is not sensitive to isoluminant contour. This analysis suggests that a solely hue-produced Müller-Lyer figure would be processed in the parvocellular channels, thus eliminating any contribution to the illusion made by depth information or contour displacements created by magnocellular interactions. In consistency with this argument, Livingstone and Hubel (1987) have reported, on the basis of informal observation, a diminution in the hue-produced Müller-Lyer illusion; they maintain that this finding supports the attribution of the illusion to inappropriate depth-cue scaling. It is important, however, that previous quantitative investigations of isoluminant Müller-Lyer figures (Gregory, 1977; Pollack, 1970; Youn, Lambert, \& Pollack, 1987) have not reported that such figures produce a smaller illusion.

In the present study, we employed a conventional psychophysical procedure to determine the magnitude of the Müller-Lyer illusion produced by red and blue figures with and without a difference in lightness between figure and ground. The figures were viewed both foveally and parafoveally. If isoluminant figures eliminate depth-cue scaling and other size-distorting processes emerging from magnocellular interactions, the resulting illusion should be reduced relative to the one produced by the figure having a common color with the ground but including a difference in lightness between figure and ground. Also, since the effects of centration (Piaget, 1969) and assimilation (Pressey, 1974; Pressey \& Kersten, 1989; Pressey \& Murray, 1976) increase as the illusion figure approaches the center of the attentive field, it can be hypothesized that the foveally positioned figures will produce larger illusions.

\section{METHOD}

\section{Subjects}

Two trained observers, F.T. and T.J., 23 and 26 years old, participated. Each had a visual acuity of $20 / 20$ as measured by a Master Orthorator.

\section{Stimuli}

We prepared eight sets of $1950 \times 50 \mathrm{~mm}$ cards. On each card, we mounted an overestimated (wings-out) Müller-Lyer figure and a single comparison line (an example is presented in Figure 1). In four sets, the face of the card provided an N5 Munsell gray background for the illusion figure; in the other sets, the background was an N7.5 gray. The length of the central line of the illusion figure was $22 \mathrm{~mm}$; the length of the oblique lines, which formed a $135^{\circ}$ angle with the central line, was $5 \mathrm{~mm}$. The comparison lines in each set of cards ranged from 20 to $29 \mathrm{~mm}$ in .5-mm interval steps. The comparison lines, as well as the lines that constituted the MüllerLyer figures, were all $1 \mathrm{~mm}$ in width.

Equal numbers of Müller-Lyer figures with comparison lines of a matching hue were constructed from red (5R5/6) and blue (5B5/6) Munsell paper. For the half of the red and blue figures that were placed on the Munsell N5 background, the contours of the stimulus were generated solely by a hue difference with the ground; for the half mounted on the N7.5 background, the contours had a hue difference and a small lightness difference with the ground.

For each combination of figural color with lightness of background, cards for foveal and parafoveal viewing were devised. For the foveal stimuli, the illusion figure and comparison line were

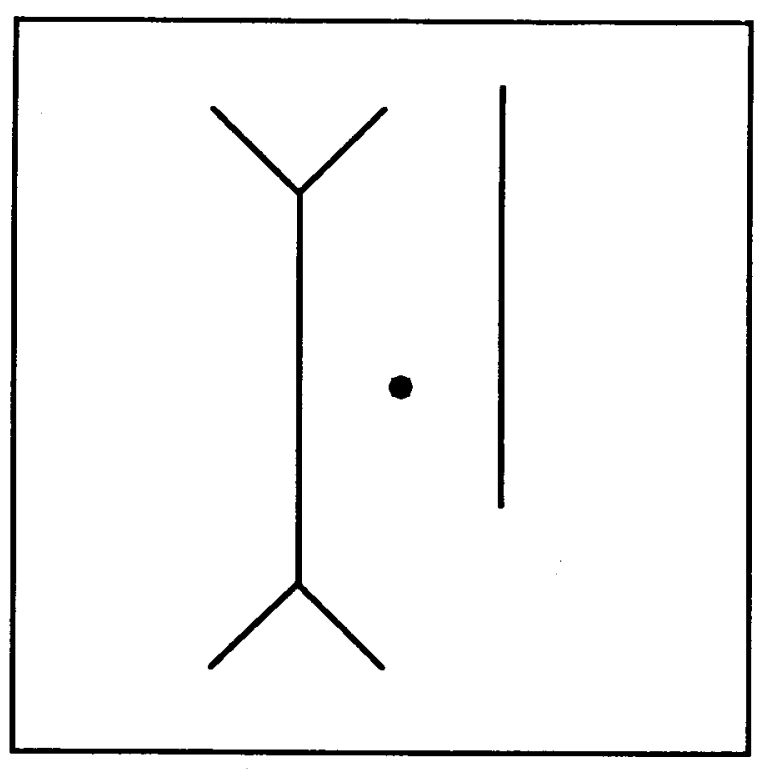

Figure 1. A foveal (left) and parafoveal (right) Müller-Lyer figure like those employed in the experiment.

mounted $5 \mathrm{~mm}$ on either side of a fixation point that was located at the center of the card. For the parafoveal stimuli, the illusion figure was located with its central line $8 \mathrm{~mm}$ from the left edge of the card and with the comparison line $10 \mathrm{~mm}$ farther to the right. The fixation point was centered vertically $8 \mathrm{~mm}$ from the right edge of the card. From the viewing distance of $1,500 \mathrm{~mm}$, the height of the stimulus reached a maximum visual angle of $1^{\circ} 7^{\prime}$. The width of the illusion figure and comparison line designed for foveal viewing subtended a visual angle of $30^{\prime}$; the width of the parafoveal stimuli was $1^{\circ} 35^{\prime}$.

In addition to the illusion stimuli, control stimuli with either red or blue lines mounted on an N5 gray ground were constructed. These stimuli consisted of a single test line $22 \mathrm{~mm}$ long and a comparison line of matching color, which ranged in length from 18 to $26 \mathrm{~mm}$ in .5-mm interval steps. The test and comparison lines were located $5 \mathrm{~mm}$ to the left and right, respectively, of the fixation point placed at the center of the card.

\section{Procedure}

The two observers viewed the illusion and control stimuli in illuminant $\mathrm{C}$ light from the eyepiece of an electronic tachistoscope (Gaertner Scientific Corporation, Chicago). The intensity of illumination at the eyepiece was $12.54 \mathrm{~lm} / \mathrm{m}^{2}$.

At the beginning of each experimental session, an illusion figure with one combination of lightness contrast and viewing position was selected. For a given session, both red and blue stimuli were employed, and the subject sat through four sets of convergingmethod-of-limits trials. Each set included two control trials of 17 judgments each, followed by four experimental trials of 19 judgments each, followed again by two control trials of 17 judgments each. The control and illusion stimuli were exposed for 1,500 msec. After each presentation, a response of "longer" or "shorter," depending on the apparent length of the comparison line relative to that of the central line of the illusion figure, was recorded. The daily sessions were continued for each subject until 10 measures of strength of illusion in each experimental condition were obtained.

In order to ensure further that our results could not have been caused by some stimulus artifact such as the detection and perception of a ridge formed by the figure pasted on the ground, we placed 
a vertical N5 gray figure on a binocular N5 ground lit by illuminant $C$ at a binocular viewing distance of $150 \mathrm{~cm}$. The dimensions of the figure and ground were identical to those described above. Each of 10 subjects with $20 / 20$ visual acuity was shown the display without exposure time limits. They were asked to describe the display. None of them detected the figure. They were then told that there was a figure present and were asked to search for it and locate it. None were able to do so. There were no perceptible ridges.

\section{RESULTS}

A point of subjective equality (PSE), defined as a change in response maintained for three consecutive judgments, was calculated for each trial. The magnitude-ofillusion scores in each session for a given combination of hue, lightness contrast, and viewing position were then obtained by subtracting the mean PSE of the control trials from the mean PSE of the experimental condition. Averaging these scores across sessions for each subject produced the data shown in Figure 2.

The magnitude-of-illusion scores obtained in each session were analyzed separately for each subject with a three-way repeated measures analysis of variance. Significant main effects of lightness were found for both Subject F.T. $[F(1,9)=13.638, p<.01]$ and Subject T.J. $[F(1,9)=35.699, p<.001]$. Also, both Subject F.T. $[F(1,9)=7.238, p<.05]$ and Subject T.J. $[F(1,9)=$ $7.183, p<.01]$ produced significant viewing position $\times$ color interactions. In addition, the data of Subject T.J. yielded a significant two-way lightness $\times$ viewing position interaction $[F(1,9)=25.544, p<.001]$ and a significant three-way lightness $\times$ viewing position $\times$ color interaction $[F(1,9)=17.897, p<.01]$. Finally, Subject F.T. added a significant two-way lightness $\times$ color interaction $[F(1,9)=62.904, p<.001]$.

\section{DISCUSSION}

The major finding, discernible from the data of both subjects, is that colored Müller-Lyer figures with no lightness differences between figure and ground produce larger illusions than do comparably colored figures that do have a lightness difference between figure and ground. The strength of these hue-induced illusions is consistent with the results of previous studies (Pollack, 1970; Youn et al., 1987 ) in which the same method of presentation was utilized, and they are consistent as well with Gregory's (1977) observation that a red figure against a green ground of matching brightness produced a robust illusion. However, the greater magnitude of hue-produced illusions is contrary to Livingstone and Hubel's (1987) finding that isoluminant Müller-Lyer figures generate smaller illusions than do those that include a difference in lightness between figure and ground. Currently it is difficult to resolve this empirical inconsistency, but it can be noted that Livingstone and Hubel do not report having used a formal psychophysical method; and their method of presenting the Müller-Lyer figure was different, for they relied on a computer-generated image.

Aside from methodological matters, the relative strength of the colored Müller-Lyer illusions produced from figures with and without lightness differences between figure and ground has important theoretical implications. Recall that it was argued that matching figure and ground lightnesses should eliminate any contribution to the Müller-Lyer illusion that results from depth-cue scaling or from contour displacements generated by magnocellular interactions. If the magnitude of the Müller-Lyer illusion were simply determined by the composite actions of sensory and cognitive processes, the elimination of a subset of

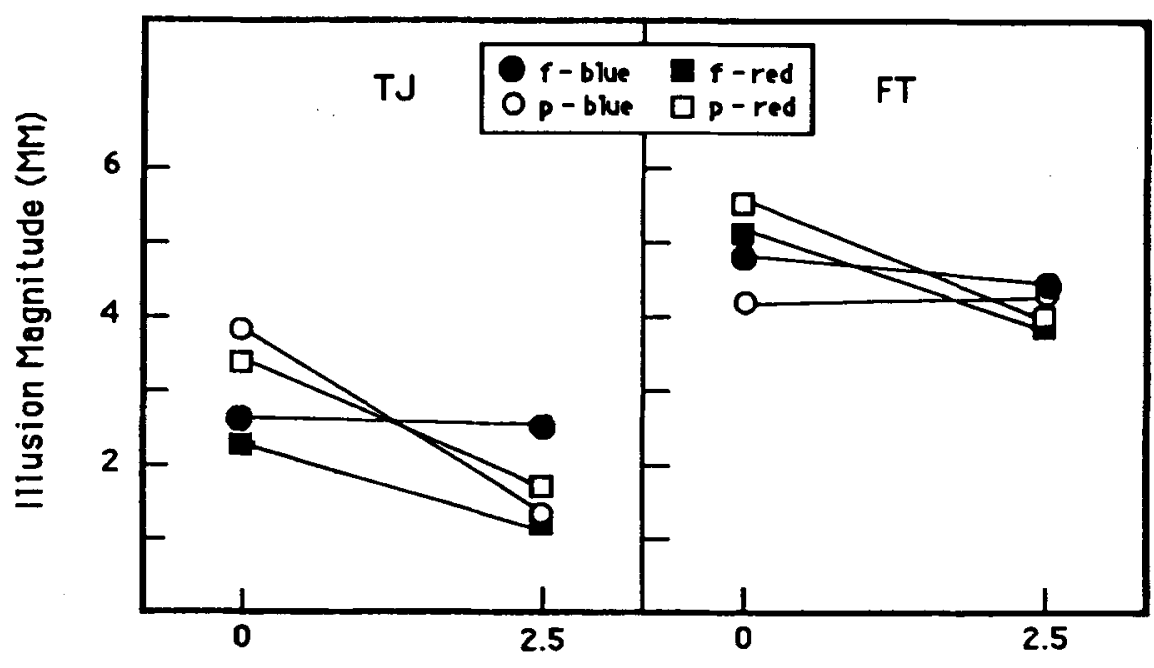

Controst (Munsell Units)

Figure 2. Hlusion magnitude as a function of lightness. Each data point is the average of 10 measurements, each measurement having been obtained from four control and four experimental trials. 
these processes should leave the hue-induced illusions weaker than those produced by figures with a lightness difference between figure and ground. However, the finding here, that a small lightness difference reduced, rather than enhanced, the illusion, coupled with previous demonstrations (Dewar, 1967; Ebert \& Pollack, 1972a, 1972b) that contour contrast is directly related to the strength of achromatic Müller-Lyer illusions, suggests that the small lightness difference between figure and ground that was used here may be governing the magnitude of the colored illusions. The presence of a detectable lightness difference appears to interfere with and override the color contour mechanism. This interference and dominance suggests that the visual system prefers the luminance (magnocellular) channel, which will respond as long as its threshold is exceeded. If it is not, the parvocellular channels are free to respond and to produce the robust isoluminant illusions obtained. Such an interpretation is consistent with Gregory's (1977) assertion that the luminance (i.e., magnocellular) channel provides a master signal utilized to synchronize the location of colored contours, and it suggests that the traditional Müller-Lyer illusion, produced by an achromatic figure, results from contour interactions within the magnocellular system.

With respect to the illusions produced by figures with only hue differences, the absence of the aforementioned synchronizing signal would seem to leave cognitive processes such as assimilation and centration largely responsible for the overestimation of the central line. Since these purely colored illusions are as large as those produced by achromatic figures under similar viewing conditions (Pollack, 1970; Youn et al., 1987), it is quite possible that multiple processes are contributing to the illusion. However, the fact that parafoveal figures, which are off center in the viewer's attentive field, do not produce reliably smaller illusions than the foveal ones do, fails to substantiate the presence of cognitive contributions based on assimilation (Pressey, 1967, 1971; Pressey \& Kersten, 1989) or enlargement by centration (Piaget, 1969). Indeed, it now seems necessary to question Gregory's (1977) argument that the existence of a robust, hue-produced Müller-Lyer illusion is indicative of a primary cognitive origin for the illusion, and to suggest instead that these hue-produced illusions may be largely attributable to contour interactions occurring within the color-coding, parvocellular channels of the visual system. Evidence of these contour interactions may surface in future research involving manipulations of such properties of the Müller-Lyer figure as hue and saturation while a lightness match between figure and ground is maintained.

\section{REFERENCES}

Brigell, M., \& UhlariK, J. (1979). The relational determination of length illusions and length aftereffects. Perception, 8, 187-197.

Brigell, M., Uhlarik, J., \& GoldhoRN, P. (1977). Contextual influences on judgments of linear extent. Journal of Experimental Psychology: Human Perception \& Performance, 3, 105-118.
BrigneR, W. L. (1977). Mathematical model for assimilation and contrast in the perception of extent. Perceptual \& Motor Skills, 45, 103-118.

Coren, S. (1970). Lateral inhibition and geometric illusions. Quarterly Journal of Experimental Psychology, 22, 274-278.

Coren, S., Girgus, J. S., Eruchman, H., Hakstian, A. R. (1976). An empirical taxonomy of visual illusions. Perception \& Psychophysics, 20, 129-137.

Coren, S., \& Porac, C. (1984). Structural and cognitive components in the Müller-Lyer illusion assessed via Cyclopean presentation. Perception \& Psychophysics, 35, 313-318.

COREN, S., WARD, L. M. (1979). Levels of processing in visual illusions: The combination and interaction of distortion-producing mechanisms. Journal of Experimental Psychology: Human Perception \& Performance, 5, 324-335.

DEwar, R. E. (1967). Stimulus determinants of the magnitude of the Mueller-Lyer illusion. Perceptual \& Motor Skills, 24, 708-710.

Ebert, P. C., \& Pollack, R. H. (1972a). Magnitude of the MuellerLyer illusion as a function of hue, saturation, and fundus pigmentation. Psychonomic Science, 26, 225-226.

Ebert, P. C., \& Pollack, R. H. (1972b). Magnitude of the MuellerLyer illusion as a function of lightness contrast, viewing time, and fundus pigmentation. Psychonomic Science, 26, 347-348.

Erlebacher, A., \& SekUler, R. (1969). Explanation of the MuellerLyer illusion: Confusion theory examined. Journal of Experimental Psychology, 80, 462-467.

Ganz, L. (1966). Mechanism of the figural aftereffects. Psychological Review, 73, 128-150.

GILlAM, B. (1980, January). Geometrical illusions. Scientific American, 242(1), 102-111.

Girgus, J. S., Coren, S., Durant, M., \& Porac, C. (1975). The assessment of components involved in illusion formation using a longterm decrement procedure. Perception \& Psychophysics, 18, 144-148.

Greist-Bousquet, S., SchiffMan, H. R. (1981). The role of structural components in the Mueller-Lyer illusion. Perception \& Psychophysics, 30, 505-511.

GREGORY, R. L. (1963). Distortion of visual space as inappropriate constancy scaling. Nature, 199, 678-679.

GreGory, R. L. (1968, November). Visual illusion. Scientific American, 219(5), 66-76.

GREGORY, R. L. (1977). Vision with isoluminant color contours: 1. A projection technique and observations. Perception, 6, 113-119.

Livingstone, M. S., \& Hubel, D. H. (1987). Psychophysical evidence for separate channels for the perception of form, color, movement, and depth. Journal of Neuroscience, 7, 3416-3468.

Livingstone, M. S., \& HubEL, D. H. (1988). Segregation of form, color, movement, and depth: Anatomy, physiology, and perception. Science, 240, 740-749.

PIAGET, J. (1969). The mechanisms of perception. London: Routledge \& Kegan Paul.

Pollack, R. H. (1964). The effects of fixation upon the apparent magnitude of bounded horizontal extent. American Journal of Psychology, 77, 177-192.

Pollack, R. H. (1970). Mueller-Lyer illusions: Effect of age, lightness contrast, and hue. Science, 170, 93-95.

Pollack, R. H., \& Chaplin, M. R. (1964). Effects of prolonged stimulation by components of the Mueller-Lyer figure upon the magnitude of illusion. Perceptual \& Motor Skills, 18, 377-382.

Predebon, J. (1986). On the dot forms of the Poggendorff and MuellerLyer illusions. Perception, 15, 483-490.

Pressey, A. W. (1967). A theory of the Mueller-Lyer illusion. Perceptual \& Motor Skills, 25, 569-572.

Pressey, A. W. (1971). An extension of assimilation theory to illusions of size, area, and direction. Perception \& Psychophysics, 9, 172-176.

Pressey, A. W. (1974). Evidence for the role of attentive fields in the perception of illusions. Quarterly Journal of Experimental Psychology, 26, 464-471.

Pressey, A. W., \& Kersten, B. (1989). Attention and the MuellerLyer illusion: Simulation of an experiment by Larsen and Garn. Perceptual \& Motor Skills, 68, 1323-1329. 
Pressey, A. W., \& MURRay, R. (1976). Further developments in the assimilation theory of geometrical illusions: The adjacency principle. Perception \& Psychophysics, 19, 536-544.

SADZA, K. J., \& DE WEERT, C. M. M. (1984). Influence of color and luminance on the Müller-Lyer illusion. Perception \& Psychophysics, 35, 214-220.
WeNDEROTH, P., \& WADE, N. (1981). An investigation of link and dot forms on the Müller-Lyer and Poggendorff illusions. Quarterly Journal of Experimental Psychology, 33, 77-85.

Youn, G., Lambert, A., Pollack, R. H. (1987). The life-span trend in the magnitude of the Mueller-Lyer illusion as a function of hue and age. Experimental Aging Research, 13, 53-56.

(Manuscript received February 2, 1989;

revision accepted for publication March 27, 1991.) 